\title{
An evidence-based approach to measuring affective domain development
}

\section{Abstract}

\section{Background}

Educational taxonomies such as those developed by Bloom et al., Krathwohl et al., and Steinaker and Bell are utilised within nursing programmes to design curriculum, develop learning objectives, and measure attainments. This includes the assessment of values, behaviours, and attitudes student nurses should hold; known as affective domain development. Measurement of the affective domain is limited and relies on quantitative tools, often assessing attitudinal change before and after learning activities. These tools fail to explore longer term impact and subtle nuances that a qualitative approach could offer. This paper examines the reliability of a qualitative framework to assess the long-term impact of learning activities known to stimulate affective domain development.

\section{Method}

Drawing on Epstein's (1977) work on affective domain development a qualitative framework that assesses modification in values, attitudes and beliefs was utilised. The framework was applied to the responses of twelve international nurses (20-24 months post nurse registration) who during their preregistration programme had engaged in learning activities considered to be enrichment (international placement, interprofessional learning, simulation and blended learning). Using the framework two researchers independently graded the responses of the participants.

\section{Results}

Analysis of the data highlighted that modification in affective domain development was measured to identification for four nurses (assuming a different attitude or behaviour) and internalisation stage for eight nurses (embracing new values and attitudes). The integration and refinement of data identified that the underlying motivating reason to participate in a learning activity and reflection were determining factors to move attitudes and values to be internalised and embedded.

\section{Conclusion}

Epstein's framework is a reliable tool that can capture the short and long-term modification in affective domain development of nurses after they have experienced transformational learning activities. Key elements appear to be, that to move a nurse from identification to internalisation level, the motivating reason for undertaking the activity must include self-awareness and reflection on the learning is undertaken by a skilled facilitator using premise reflection. However, further research is required which utilises the framework in a longitudinal study with a larger cohort. 


\section{Introduction}

Quality has become a blueprint for the delivery of patient care (Scoville et al. 2016; Brown 2011). Yet, how nurse's values affect the therapeutic relationship in assuring quality of patient care, despite being critical to the process is rarely considered (Shultz, 2009). For many years nursing and education has recognised that morals and values affect clinical decision making in complex situations: leading to the introduction of cognitive, psychomotor and affective learning domains (Krathwohl et al. 1964). The development of attitudes, values, motivation, beliefs, and emotions (Savickiene 2010); more importantly affective domain measurement is the focus of this paper.

The transformation of nursing education across different countries calls for evidence-based pedagogies that address professional values acquisition (McAllister 2015; Willis 2012; Benner, Sutphen, Leonard, and Day 2010). Current evidence on affective domain development provides thoughts on learning interventions but fails to address the need for evidence based educational interventions (Taylor 2014). Measuring changes in values, attitudes, and behaviour of student nurses, is a challenge. This is confounded by a lack of affective domain research (Rogers, May, Chan and Miller 2017; Ritchie 2003), with less than reliable measurement instruments enabling replication, and often evaluations occurring immediately after the intervention (Valiga and Ironside 2012).

Brown and Ferril (2009), Neuman, Allen, and Friedman (2010), and Miller (2010) have all developed taxonomies for health and social care workers that they suggest would address affective domain development. However, these taxonomies are purely theoretical and non-present a measure for the extent of affective domain development. A review of the literature on current measurement tools available proffer both quantitative and qualitative instruments.

A qualitative method to address this deficit of measurement tools was reported on by Hanson (2011) who used critical incident questionnaires to measure affective domain development of final year nursing students. She drew upon Diekelmann's (2001) Concernful Practices of Schooling Learning Teaching and transformative learning theory to deliver a lecture on her experience of nursing patients in the Bali bombings to 76 students. The purpose was to enable to students to understand how nurses learn to practice and build their resilience in coping with critical incident situations and stimulate self-reflection. The students were then asked to reflect on her lecture using a critical incident questionnaire; to assess, using five open ended questions, which case studies the students remembered as significant to their learning. Her findings noted the students found the lecture emotive, powerful, and they were able to link theory with practice. However, what is clearly noted is that this method of evaluation did not measure the degree of modification in affective attributes of the students. On further examination critical incident questionnaires are used to find out how students are experiencing their learning and in this instance Hanson's teaching. Therefore, offering little to the discourse of how nurse educators can measure affective domain development of their students.

Wu, Heng and Wang (2015) propose that authentic assessment rubrics (a quantitative measure) allow educators to measure student's knowledge, skills and attitudes. This method involves the creation of case scenarios with supportive guidance which grade performance as criterion. In their mixed methods study small groups of students were asked to analyse a clinical case and generate decisions about the care the patient should receive. One student then role played a simulated assessment and carried out an intervention on behalf of other students in their group. This process was then self, and peer assessed by the students using the rubric and performance assessment task. Wu et al. (2015) found, through an open-ended survey and focus groups, with sixteen of the original 
participants; that authentic assessment rubrics helped students to clarify goals of a learning activity and clearly know what excellent nursing care was. In relation to caring attributes peer feedback helped the students become aware of their verbal and nonverbal communication skills and the importance of caring skills. Whilst the advantages of using rubrics was clear, how reliable the rubric is as a measurement tool of attitudes, values, and behaviours is not evident. For example, rubrics can restrict a student's development as they feel the need to complete the assessment strictly to the rubric instead of taking the initiative to explore other decisions; it is challenging to provide consistent grading schemes within a rubric as they often are not detailed enough, consensus across attributes varies and consistency across assessors using the rubric is low (Villarroel et al. 2017)

To evidence an instrument that could assess affective learning Rogers, Mey, Chan, Lombard and Miller (2018) used a mixed method approach to validate the Griffith University Affective Learning Scale, a seven-point Likert Scale that incorporated Krathwohl et al. (1964) five stages of affective domain development. The scale was then used by trained facilitators to rate the degree of affective learning of twenty-five medical students who completed five reflective diary journals each day whilst participating in a week long immersive simulation activity. Consensus of theorist's over time suggests that values, attitudes and beliefs cannot be graded (King 1984; Reilly 1978: Krathwohl et al. 1964). However, the judgement and comprehensiveness of the rationale for the student's opinion can be graded (Reilly 1978). Indeed Krathwohl et al. (1964) had not intended the stages of affective domain development to be used as a scale, but Rogers et al. (2018) suggest otherwise. Whilst Rogers et al. (2018) present a practical scale with a degree of interrater reliability and face validity, for simulation and reflective journals use, the evidence is limited to assessing one learning activity and one profession specific group of a small sample size, by assessors soon after training. The student reflections were self-reported, which can lead to response bias and response compliance (students reporting what the teacher wants to hear) self-promotion or lack of self-awareness (Morrow, Jackson, Disch and Mood 2011; McDonald 2009). However, the authors do report that they did not share the tool so as not to bias their findings from students who write to the rubric. As the selfreported reflections were written during the week of the learning activity they only report on intentions to change practice and not reports where practice had changed, limiting the efficacy of the scale to assess sustained change. Also, Krathwohl et al. (2001) scale focuses on changing values and behaviour only and not transformation of attitudes, values, motivation, beliefs, and emotions which is more congruent with current codes of professional conduct (NMC 2015).

To try to capture logic and rationale, Epstein's (1977) conceptual framework which grades and characterises learning in the affective domain in three stages, proves a useful alternative to Krathwohl et al. (1964) and Rogers et al. (2018) scales. Categorised by a three-staged process development of values, attitudes and behaviour are measured from the influence of types of communication. This allows the measurement of all affective constructs (attitudes, values, motivation, beliefs and emotions), simplifies measurements into three stages and can record changes in practice. As the scale is qualitative in nature it captures subtle distinctions in affective domain development when measuring outcomes of transformational learning activities.

- Stage 1. Compliance - assuming or conforming to a recognised professional attitude or behaviour in order to gain approval or avoid punishment.

- Stage 2. Identification - assuming a different behaviour and attitude to preserve a rewarding relationship with individuals or groups.

- Stage 3. Internalisation - embracing of new values and attitudes because the transformation is intrinsically rewarding and is congruent with their value system and not to please others. 
When the framework was used to measure the impact of enrichment activities on nurses five variables were exposed (Stephens 2015; Stephens and Ormandy 2018). To achieve internalisation (stage 3), of new attitudes, values, motivation, beliefs, and emotions congruent with the nursing profession educational activities should address: personal/professional, or academic goals of the student, are based on cultural encounters within real clinical situations, repeated over time, and involve premise reflection. Using this framework to grade learning activities corroborated and reinforced the notion that potential affective domain measurements could be derived (Wu et al. 2015; Rogers et al. 2017; 2018). The method of grading affective domain development through selfreported responses appears to be gaining interest and robust evidence emerging measuring the presence and quality of affective learning not only amongst nursing students, but other professions. This paper expands theory and current evidence by further examining the application of Epstein's affective domain conceptual framework on the grading of affective domain development in nursing education. This study is novel in that it tests the stability of the framework and affective domain development impact over a longer time frame (20-24 months post intervention). Evidence of whether affective domain development is sustained is limited and graded measurement's just emerging.

\section{Method}

The purpose of the study was to test the reliability of Epstein's framework in assessing the long-term impact of learning activities known to stimulate affective domain development, 20-24 months post nurse registration. Ethical approval through the University Research Ethics panel was obtained.

\section{Recruitment strategy}

Recruitment was from a target population of 105 nurses from seven countries who had participated in different enrichment activities over a two-month period using social media and email. Twelve nurses were recruited to the study. A small qualitative sample such as this can be considered credible to interpret meaningful themes particularly if the sample is homogenous (Baum 2002; Guest et al. 2006), combined with purposive sampling it can provide richness of data (Ezzy 2002).

\section{Data collection}

After written consent was obtained, video conference interviews were digitally recorded (lasting 3045 minutes). Employed so as to be time efficient, financially resourceful and to pick up on gestures, facial expressions, posture and tone of voice (La lacona, Symonds, and Brown 2016). An interview schedule used open ended questions to guide the interview and prompted discussion regarding the impact of the educational activities on professional and personal values and attitudes.

The researcher encouraged the nurses to discuss their experiences and assured confidentiality of discussions during and after the interview, particularly anonymity when writing up quotes, and paraphrasing words from interview dialogue. Recorded interviews were stored on password protected computer, numbered with a research code then transcribed for analysis. All data was coded and anonymised, with personal details stored separately.

\section{Data Analysis}

Data was analysed as in two previous studies by grading the nurses responses using Epstein's (1977) three stages compliance, identification and internalisation (Stephens 2015; Stephens and Ormandy 2018). Data was organised by demographics, impact on attitude, value, or behaviour, and level of 
affective domain development coded to each comment (Table 1). Data credibility was increased when coded separately by a second independent researcher, then analytical themes compared, corroborated and consensus on grading Epstein's stages achieved (Thomas and Harden 2008).

\section{Findings}

Twelve nurses were recruited to the study: five male, seven female, from across five countries: Cyprus, England, Finland, Germany, and Spain. The nurses (and a qualified nurse fireman) were 2024 months' post registration, all participated in an enrichment learning activity in their final year as a student nurse.

When the framework was applied to the interview responses of the participants modification of affective domain could be measured including classification of higher levels of affective learning and impact on clinical practice. There were no gender differences observed in levels of modification of affective domain development graded.

Interplay across the data was isolated when investigating relationships between: the types of enrichment activities; the nurse's reasons for engaging in the activity; the nurses self-reported change in values, attitudes, or behaviours; and the level of affective domain development achieved (Table 1). None of the nurses recruited were graded to be at Epstein initial stage of compliance, just simply conforming to a recognised professional attitude. Four nurses following the discussion and exploration of their experiences had reached Epstein's identification stage 2, describing a change in their behaviour/attitude to different individuals or groups because of the intervention. Eight nurses demonstrated reaching internalisation stage 3 , embracing new values and attitudes because the transformation of the learning was rewarding and corresponded to their value system. Exploration of these changes and affective domain development within the rich qualitative data highlighted that progression from identification to internalisation stage, required the nurse's original motivating reward or incentive to include self-awareness development. In addition, there needed to be reflection on the learning from the enrichment activity, undertaken by a skilled facilitator using premise reflection.

\section{Discussion}

There is a call to address the current dearth of literature in affective domain research in particular evidence on reliable measurement instruments (Rogers et al. 2017; Valiga and Ironside 2012; Ritchie 2003). Epstein's (1977) framework was applied to the responses of nurses who had engaged in enrichment learning activities during their nurse training measuring the degree of modification in values, attitudes and beliefs longer term. This paper extends existing knowledge exploring the longer-term impact of enrichment activities generating evidence of the utility value of Epstein's framework as a tool for grading and measuring modification in affective domain development. Indeed, findings highlighted that modifications in affective domain can be measured including classification of higher levels of affective learning and impact on clinical practice.

In comparison to critical incident questionnaires as utilised by Hanson (2011) Epstein's framework offers a reliable tool that truly measures the impact a learning activity has on the affective domain development of students themselves and not an evaluation of how students are experiencing learning and teaching. 
In contrast to the use of authentic assessment rubrics by Wu, Heng and Wang (2015), Epstein's framework does not restrict a student's development, as assessment of qualitative feedback allows the respondent to demonstrate where they may have taken the initiative to explore other decisions and not conform only to attributes in a rubric. Epstein's framework also allows educators to collect detailed data on the impact of learning experiences on affective domain development in a greater depth than a quantitative measure.

Rogers et al. (2018) scale corroborates the need for a qualitative measure to be applied to the reflections of respondents to effectively assess affective domain development of students. However, it utilises a scale not meant for this purpose and therefore limits assessment of affective domain development. By grading the changing of values and behaviour only, Rogers adapted scale fails to provide an assessment of a transformation of attitudes, values, motivation, beliefs, and emotions, potentially simplifying affective domain development to different types of conformity (Kelman 1958). Epstein's framework however, offers educationalists a simplistic tool that both grades and characterises affective domain development and also record changes in practice. Furthermore, Rogers et al. (2018) scale measured the impact of affective domain development for one profession after a week's simulation learning experience. Whereas Epstein's framework has been used to measure affective domain development across many professional groups and the impact of multiple learning activities. Both studies nonetheless emphasize the importance of repeated learning activities incorporating reflection aid affective domain development. However, interplay amongst the types of activities, the reasons for engaging in the activity and self-reported change in values, attitudes, or behaviours, and the level of affective domain development reached is only recorded when Epstein's framework is applied. Also, by conducting reflective interviews and grading and characterising affective domain development the authors of this study were able to expose advancement from identification to internalisation level occurred when the nurse's initial motivating reward or incentive contained self-awareness development and the practice of premise reflection was with a skilled facilitator. Transformative learning signifies the process when students 'frames of reference' are transformed to enable them 'to make them more open, emotionally capable of change and reflective so that they may generate beliefs and opinions that will prove more true or justified to guide action' (Mezirow and Associates 2000, p.7-8). Epstein's framework can measure this transformative change enabling the distinction and movement from compliance to identification to internalisation and the embracing of new values as part of a belief system (Epstein 1977). Nurses were asked to provide examples of changes in themselves both personally and professionally. Epstein's framework helped to assess whether the nurse's responses were conforming to the interviewers questioning or embracing new attitudes, values and belief system. In comparison to Krathwohl et al. (1964) scale amended by Rogers et al (2018), Epstein's levels link to the elements of premise reflection; content, process and premise. (Kreber and Cranton 2000). Content reflection assists with the description of beliefs about what is already known by a person, exploring any actions they may have taken, and challenging their current assumptions and bodies of knowledge, validating what they might have done (compliance stage). Process is gathering data that underpins practice which is then measured in benefits and outcomes (identification stage). However, participating in premise reflection requires examination and reconceptualising of issues, justifying approaches taken or suggesting alternatives and requires the ability of self-examination in depth (internalisation stage). This is important to the aim of this paper as it provides new insights into operationalising Epstein's framework as a tool to measure affective domain development in nurse education. The key elements required to stimulate, and measure affective domain development are highlighted in table 2. 
Future research could examine the use of Epstein's framework in comparison to Rogers et al. scale within a qualitative longitudinal approach with a larger cohort, measuring affective domain development from the start of a nursing programme with follow up twelve months post registration.

As already noted in a previous study Epstein's tool is not exclusive to nurses but could easily be adapted other professions. As Epstein's framework was developed using the English language it would be interesting to explore the value of the tool across other languages.

\section{Conclusion}

The study sought to respond to the calls for more robust tools to measure modification of the affective domain (Rogers et al. 2017; Taylor 2014; Valiga and Ironside 2012; Brown 2011). This study not only corroborates and builds on the current evidence base but has established a method that enables measuring of affective domain development and addresses the need to be able to classify higher levels of affective learning and impact on clinical practice. The findings also emphasize that the most effective evidence-based means in order to achieve internalisation of new attitudes, values, motivation, beliefs, and emotions congruent with the nursing profession is to ensure the motivating factor for the student undertaking the educational activity includes self-awareness development and the activity involves premise reflection.

\section{Limitations}

The study findings are limited as the sample was targeted, small, self-selecting and self-reporting. The participants may be more likely to be aware of the potential benefits of enrichment activities on their values, attitudes, and behaviours.

\section{References}

Asch, S. E. (1951). Effects of group pressure upon the modification and distortion of judgment. In Guetzkow, H. (Ed.) Groups, leadership and men. Pittsburgh, PA: Carnegie Press.

Baum, F. (2000) The New Public Health. Oxford: Oxford University Press.

Benner, P., Sutphen, M., Leonard, V., \& Day, L. (2010). Educating nurses: A call for radical transformation. San Francisco, CA: Jossey-Bass.

Bloom, B. S., Engelhart, M. D., Furst, E. J., Hill, W. H., and Krathwohl, D. R. (1956). Taxonomy of educational objectives: The classification of educational goals. Handbook I: Cognitive domain. David McKay Company: New York.

Brown, L.P. (2011). Revisting our roots: Caring in nursing curriculum design. Nurse Education in Practice, 11, pp.360-364.

Brown, D., \& Ferril, M.J. (2009) The Taxonomy of Professionalism: Reframing the Academic Pursuit of Professional Development. American Journal of Pharmaceutical Education. 73, (4), 1-9.

Data Protection Act 1998. 
Diekelmann, N. (2001). Narrative pedagogy: Heideggerian hermeneutical analyses of lived experiences of students, teachers, and clinicians. Advances in Nursing Science, 23 (3), pp.53-71.

Epstein, R. (1977) Evaluating the effective domain of student learning. National League for Nursing: Evaluation of Students in Baccalaureate Nursing Programs. NLN: New York.

Ezzy, D. (2002) Qualitative Analysis: Practice and Innovation. Crows Nest, NSW: Allen \& Unwin.

Guest, G., Bunce, A., and Johnson, L. (2006), “How many interviews are enough? An experiment with data saturation and variability", Field Methods, 18(1), pp. 59-82.

Hanson, J. (2011). Advancing affective attributes and empowering undergraduate students - lessons learned from the Bali bombing. Nurse Education in Practice, 11, pp.411-415.

King, E. C. (1984) Affective education in nursing. A guide to teaching and assessment. Aspen Systems Publishers: Maryland.

Krathwohl, D.R, Bloom, B.J., and Masia, B.B. (1964) Taxonomy of educational objectives: Handbook II. Affective domain. David McKay Co: New York.

Kreber, C. \& Cranton, P. A. (2000). Exploring the scholarship of teaching. Journal of Higher Education, $71(4)$, pp.476-496.

Lo lacona, V., Symonds, P. and Brown, D.H.K. (2016) Skype as a Tool for Qualitative Research Interviews. Sociological Research Online, 21 (2), 12. http://www.socresonline.org.uk/21/2/12.html DOI: $10.5153 /$ sro.3952

McAllister M. (2015) Exploring transformative learning and courage to teach a values-based curriculum. Nurse Education in Practice. 15(6), pp.480-4.

McDonald, Michael J., "Voice and Volume of Leader Self-Awareness" (2009). Educational Administration: Theses, Dissertations, and Student Research. 12. Retrieved $1^{\text {st }}$ June 2018 https://digitalcommons.unl.edu/cehsedaddiss/12/?utm_source=digitalcommons.unl.edu\%2Fcehsed addiss\%2F12\&utm_medium=PDF\&utm_campaign=PDFCoverPages

Mezirow, J. and Associates. (2000) Learning as transformation. Critical perspectives on a theory in progress. San Francisco: Jossey-Bass.

Miller, C. (2010) Literature review: Improving and enhancing performance in the affective domain of nursing students: Insights from the literature for clinical educators. Contemporary Nurse. 35. (1), pp.2-17.

Morrow, J.R., Jackson, A., Disch, J.G., and Mood, D.P. (2010) Measurement and Evaluation in Human Performance. Human Kinetics Publishers:

Neuman Allen, K., \& Friedman, B.D. (2010) Affective learning: A taxonomy for teaching social work values. Journal of Social Work Values and Ethics. 7, (2) Retrieved 1st June 2018 from http://www.socialworker.com/jswve

Nursing and Midwifery Council (2015) The Code. NMC:London.

Reilly, D. (1978) Teaching and evaluating the affective domain in nursing programs. Slack: London

Ritchie, M.A. (2003). Faculty and student dialogue through journal writing. Journal for Specialists in Paediatric Nursing, 8(1), pp.5. 
Rogers, G., Mey, A., Chan, P., Lombard, M., and Miller, F. (2018) Development and validation of the Griffith University Affective Learning Scale (GUALS): A tool for assessing affective learning in health professional students' reflective journals, MedEdPublish, 7, (1), 2,

doi:https://doi.org/10.15694/mep.2018.000002.1

Rogers, G. D., Mey, A., \& Chan, P. C. (2017). Development of a phenomenologically derived method to assess affective learning in student journals following impactive educational experiences. Med Teach, 1-11. https://doi.org/10.1080/0142159X.2017.1372566

Savickienè, I. (2010) Conception of Learning Outcomes in The Bloom's Taxonomy Affective Domain. Quality of Higher Education, 7. pp.37-59.

Scoville, R., Little, K., Rakover, J., Luther, K., and Mate, K. (2016) Sustaining Improvement. IHI White Paper. Cambridge, Massachusetts: Institute for Healthcare Improvement.

Shultz, C. M. (Ed.) (2009). Building a Science of Nursing Education: Foundation for Evidence-Based Teaching-Learning. New York NY: National League for Nursing.

Steinaker, N.W. \& Bell, M.R. (1979) The Experiential Taxonomy: a new approach to teaching and learning, London: Academic Press.

Stephens, M. (2015) Changing student nurses values, attitudes, and behaviours : a meta ethnography of enrichment activities, Journal of Nursing and Care, 5 (320), pp.1-10.

Stephens, M., and Ormandy, P. (2018) Extending conceptual understanding: How interprofessional education influences affective domain development. Journal of Interprofessional Care. 32(3), pp.348-357 doi.org/10.1080/13561820.2018.1425291

Taylor, L.D. (2014) The affective domain in nursing education: Educators Perspectives. Thesis and Dissertations 484. University of Wisonsin, Milwaukee. Retrieved from http://dc.uwm.edu/cgi/viewcontent.cgi?article=1489\&context=etd.

Thomas, J., \& Harden, A. (2008). Methods for the thematic synthesis of qualitative research in systematic reviews. BMC Medical Research Methodology, 8, 45. http://doi.org/10.1186/1471-22888-45

Valiga, T.M., and Ironside, P.M. (2012) Crafting a National Agenda for Nursing Education Research. Journal of Nursing Education. 51(5), pp.3,6.

Villarroel, V., Bloxham, S., Bruna, D., Bruna, C., and Herrera-Seda, C. (2017) Authentic assessment: creating a blueprint for course design, Assessment \& Evaluation in Higher Education, DOI: 10.1080/02602938.2017.1412396

Willis Commission (2012) Quality with compassion: the future of nursing education. Retrieved from http://www.williscommission.org.uk/recommendations

Wu, X.V., Heng, M.A., and Wang, W. (2015) Nursing students' experiences with the use of authentic assessment rubric and case approach in the clinical laboratories, Nurse Education Today, 35, pp.1069-1073. http://dx.doi.org/10.1016/j.nedt.2014.12.009 
Table 2: Key elements for operationalising and measuring affective domain development

\begin{tabular}{|c|c|}
\hline Operational Stage & Element \\
\hline 1. & $\begin{array}{l}\text { Design transformative learning activities based around: } \\
\text { a. A new cultural encounter (IPL, International, or both) } \\
\text { b. An immersive experience for over two weeks or repeated } \\
\text { frequently over six weeks } \\
\text { c. Clinical practice }\end{array}$ \\
\hline 2. & $\begin{array}{l}\text { Students to record the motivating reason for attending the learning activity } \\
\text { and link to an aspect of self-awareness development (attitudes, values, } \\
\text { motivation, beliefs, or emotions) }\end{array}$ \\
\hline 3. & $\begin{array}{l}\text { During learning activity students are provided with regular facilitated } \\
\text { reflection sessions with skilled academic/clinician/practitioner (video } \\
\text { recorded). } \\
\text { Reflections would be based upon year of programme/exposure to } \\
\text { reflection: } \\
\text { a. Content reflection assists with the description of beliefs about what } \\
\text { is already known by a person, exploring any actions they may have } \\
\text { taken, and challenging their current assumptions and bodies of } \\
\text { knowledge, validating what they might have done. } \\
\text { b. Process is gathering data that underpins practice which is then } \\
\text { measured in benefits and outcomes. } \\
\text { c. Premise reflection requires examination and reconceptualising of } \\
\text { issues, justifying approaches taken or suggesting alternatives and } \\
\text { requires the ability of self-examination in depth. }\end{array}$ \\
\hline 4. & $\begin{array}{l}\text { Measure degree of affective domain development using Epstein's } \\
\text { framework } \\
\text { Stage 1. Compliance - assuming or conforming to a recognised } \\
\text { professional attitude or behaviour in order to gain approval or avoid } \\
\text { punishment. } \\
\text { Stage 2. Identification - assuming a different behaviour and attitude } \\
\text { to preserve a rewarding relationship with individuals or groups. } \\
\text { Stage 3. Internalisation - embracing of new values and attitudes } \\
\text { because the transformation is intrinsically rewarding and is } \\
\text { congruent with their value system and not to please others. }\end{array}$ \\
\hline 5. & Document in students personal development record. \\
\hline
\end{tabular}

